\title{
La inteligencia (noesis) en Diógenes de Apolonia
}

\section{DAVID TORRIJOS-CASTRILlEJO}

Facultad de Filosofía

Universidad San Dámaso

28005 Madrid (España)

dtorrijos@sandamaso.es

\begin{abstract}
The philosophy of Diogenes pays special attention to knowledge. Diogenes bases his thought on the well-known thesis of Parmenides which identifies einai and noein, combining it with the nous of Anaxagoras. According to Diogenes, the intellect (noesis) is embodied in the formal features of things and therefore is powerful, like the nous of Anaxagoras. The aim of the following pages is to show, in confrontation with Laks, that noesis does not homogenize the cosmos, but rather it diversifies it.
\end{abstract}

Keywords: Intellect, difference, diversity, cosmology.
Resumen: La filosofía de Diógenes presta especial atención al conocimiento. Parte de la célebre tesis de Parménides que identifica noein y einai, combinándola con el nous de Anaxágoras. En Diógenes, la inteligencia (noesis) está plasmada en los rasgos formales de las cosas y, por ello, es moviente como el nous de Anaxágoras. El objetivo de estas páginas es mostrar, en confrontación con Laks, que la noesis no homogeneiza el cosmos sino que más bien lo diversifica.

Palabras clave: Inteligencia, diferencia, diversidad, cosmología. 


\section{INTRODUCCIÓN}

E

n estas páginas pretendo centrarme en la concepción de la inteligencia (noesis) sostenida por Diógenes de Apolonia. Este presocrático otorga un protagonismo considerable a esta noción en su filosofía; no obstante es uno de los autores que, desgraciadamente, no fue atendido por von Fritz en su célebre estudio sobre el nous, noein y sus derivados en los presocráticos ${ }^{1}$. El motivo de este desdén podría deberse a la generalizada minusvaloración que ha padecido este filósofo, sobre todo desde que Diels lo calificó de "ecléctico" . Recientemente han protestado contra esta rebajada opinión tanto Laks ${ }^{3}$ como $\mathrm{Graham}^{4}$, aunque años antes Cappelletti ya había dejado escritas en español las siguientes reflexiones:

Sin sobreestimar, pues, su originalidad, [...]; sin negar siquiera su condición de epígono, es preciso reconocer en él un esfuerzo clarificador y fundamentador, que responde a las exigencias dialécticas y retóricas más elevadas de la época de los sofistas. Tales exigencias producen en él una suerte de autoconciencia del monismo jónico, como enfrentado al pluralismo de Empédocles, Anaxágoras, etc ${ }^{5}$.

1. Cf. K. vOn Fritz, NOY $\Sigma$, NOEIN, and Their Derivatives in Pre-Socratic Philosophy (Excluding Anaxagoras): Part I. From the Beginnings to Parmenides, "Classical Philology" 40 (1945) 223-242; ID., NOY 2 , NOEIN, and Their Derivatives in PreSocratic Philosophy (Excluding Anaxagoras): Part II. The Post-Parmenidean Period, "Classical Philology" 41 (1946) 12-34; ID., Der NOY $\Sigma$ des Anaxagoras, "Archiv für Begriffsgeschichte" 9 (1964) 87-102.

2. Cf. A. LaKs, Speculating about Diogenes of Apollonia, en P. Curd, D. W. Graham (eds.), The Oxford Handbook of Presocratic Philosophy (Oxford University Press, Oxford, 2008) 353.

3. Cf. A. LaKs, Diogène d'Apollonie (Academia, Sankt Augustin, 22008). La primera edición de esta obra es de 1983.

4. Cf. D. W. Graham, Explaining the Cosmos. The Ionian Tradition of Scientific Philosophy (Princeton University Press, Princeton, 2006) 277-284.

5. Á. J. CaPPElletTi, Diógenes de Apolonia y la segunda filosofía jónica (Universidad de Zulia, Maracaibo, 1976) 25. Poco antes, había afirmado: "En realidad, no hay en Diógenes un verdadero eclecticismo [...]. Su pensamiento se estructura más bien en contraste dialéctico con los pensadores pluralistas, con Empédocles, con Leucipo y, sobre todo, con Anaxágoras". ID., Los fragmentos de Diógenes de Apolonia (Tiempo Nuevo, Caracas, 1975) 5-6. También había emitido un juicio bastante 
Es ésta la singular condición de Diógenes, que no sólo es monista sino además sabedor de ello y sostiene esta tesis en respuesta a los exigentes argumentos de Parménides, como ya hizo ver oportunamente Stokes ${ }^{6}$.

El estudio de Diógenes ha estado condicionado a lo largo del siglo XX por un célebre trabajo de Theiler (1924) en el cual se fijaba en este filósofo como iniciador del razonamiento teleológico ${ }^{7}$. Sin embargo, el comentario de Laks ha introducido un cambio de perspectiva al afirmar que la filosofía de este presocrático no estaría preocupada primordialmente por resolver el problema de la teleología sino más bien por el conocimiento ${ }^{8}$. Esto posee una gran significatividad para nosotros, que pretendemos atender precisamente a este aspecto. No obstante, debido al relativamente escaso número de estudios en torno a Diógenes y a los condicionantes mencionados,

positivo Guthrie: "The ingenuity with which he adapted the various conceptions of his predecessors to a system in keeping with the most recent advances of thought compels an admiration which is scarcely conveyed by the word 'eclecticism'". W. K. C. GuThrie, A History of Greek Philosophy (Cambridge University Press, Cambridge, 1978) vol. 2, 371. Como acerba expresión de la postura contraria, cabe recordar las duras palabras de Zafiropulo: "[T]oute la faiblesse du système prôné par l'Apolloniate est évidente pour qu'il soit besoin d'y insister: glanant à droite et à gauche les idées émises par ses prédécesseurs ou par ses contemporains, il les explique toutes à l'aide de son principe aérien, le plus souvent à tort et à travers, sans se préoccuper des absurdités ni des contradictions qu'un semblable traitement faisait fréquemment naître dans les constructions qu'il empruntait sans vergogne aux meilleurs esprits de l'Hellade. Aussi demeurons-nous persuadés que Diogène serait depuis longtemps tombé dans l'oubli définitif que ses médiocres élucubrations lui auraient largement mérité, s'il n'avait, le premier, mis en avant [...] le téléologisme". J. Zafiropulo, Diogène d'Apollonie (Les Belles Lettres, Paris, 1956) 100-101. También podemos mencionar a Barnes, quien designa a Diógenes como un "essentially second-rate man", afirmando de él: "[...] he is a common butt of comedy and he had an influence on Euripidean tragedy. Such a reputation implies not stature and novelty but rather the reverse; it is unoriginal men who are thus representative". J. BARNES, The Presocratic Philosophers (Routledge, London, 1982) 567-568, cf. 583. Resulta interesante que justo la presencia de Diógenes en la comedia de Sófocles y en la tragedia de Eurípides sea interpretada por Graham de un modo opuesto, es decir, para reforzar su importancia: cf. GRAHAM, Explaining the Cosmos cit., 291.

6. Cf. S. T. STOKes, One and Many in Presocratic Philosophy (Oxford University Press, Washington, D.C., 1971) 238-244.

7. Cf. W. THeILER, Zur Geschichte der teleologischen Naturbetrachtung bis auf Aristoteles (Karl Hoenn, Zürich, 1924).

8. Cf. LaKs, Diogène d'Apollonie cit. 
la atención dedicada al conocimiento según Diógenes es de hecho bastante escasa. Ni siquiera Laks le otorga un espacio demasiado abultado, pese a creer que constituye el centro de la aportación de este filósofo.

En Diógenes encontramos una curiosa comprensión de la inteligencia, aunque, para ser precisos, menester es notar que él no se refiere al nous sino que habla de la noesis. $\mathrm{Al}$ parecer, nuestro presocrático parte de la conocida tesis de Parménides que identifica noein y einai, teniendo presente también el nous de Anaxágoras. Vemos, pues, en Diógenes cómo la inteligencia está plasmada en los rasgos formales de las cosas y, justamente por ello, posee un poder efectivo sobre la realidad, análogo al principio moviente del cual habla el filósofo de Clazomene.

En lo que sigue intentaremos penetrar, pues, en esta concepción de Diógenes, llevando a cabo así una revisión de las páginas que le dedicamos en un libro precedente, en donde lo estudiamos principalmente como 'sucesor' de Anaxágoras'. Primero vamos a examinar la función de la inteligencia tal como la entiende nuestro filósofo, partiendo de la exposición que de ella hace Laks, el estudioso que más se ha ocupado de este tema. Sin embargo, nos veremos obligados a corregir su interpretación puesto que no parece ser un principio de uniformidad en el cosmos, sino de variedad.

\section{LA NOESIS DE DiÓGENES SEGÚN LAKS}

Como decíamos, Laks ha sido el investigador que ha otorgado mayor importancia a la noesis en su comprensión de Diógenes, pues cree que el interés de este filósofo se centra primordialmente en el conocimiento y no en la teleología. En efecto, Diógenes ha afirmado que el

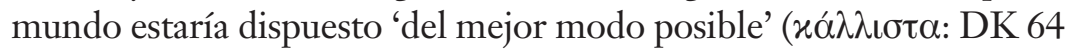
B 3, Laks 6, LM 28 D 5 b ${ }^{10}$ ). No obstante, esta expresión, aunque nos podría hacer pensar en cierta teleología, tan sólo constituye una va-

9. Cf. D. Torrijos-Castrillejo, Anaxágoras y su recepción en Aristóteles (EDUSC, Roma, 2014) 282-289.

10. Para las citas seguiré la siguiente nomenclatura: DK=DIELS-KRANZ, Laks=LAKS 22008, LM= LAKS-MOST. 
loración cuasi estética de dicha disposición (por eso se usa el adjetivo $x \alpha \lambda o ́ \varsigma)^{11}$. En este sentido, no aportaría mucho más contenido que el

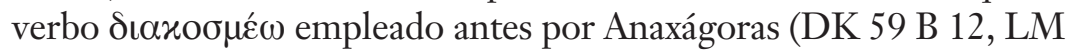
25 D 27). Ambos pensadores están convencidos de que el orden del mundo es hermoso y bueno, pero no son capaces de explicar que el mundo ha sido arreglado de tal manera precisamente porque eso era lo mejor. Carecen de una explicación teleológica en sentido estricto. Sin embargo, sus respectivas filosofías sí encierran cierta teleología, porque ambos apelan a la inteligencia como causante de dicha disposición, otorgando a ésta la capacidad de disponer y poner en orden. En efecto, lo primario en el planteamiento de Diógenes es que ese orden está estructurado en virtud de un ejercicio inteligente, pese a no estar expresamente afirmado que la inteligencia se deba guiar por 'el bien' para llevarlo a cabo. Precisamente eso será lo echado en falta por Sócrates en el famoso pasaje del Fedón (97c-98c) en que se remite a Anaxágoras: tampoco Diógenes habría satisfecho al maestro de Platón, porque tanto el primer presocrático como el segundo hablaban de 'ordenar inteligentemente', pero no de hacerlo 'por mor del bien'; luego dicho intelecto adolecería de falta de lucidez ${ }^{12}$.

Concentrarse en la leve teleología implícita en las palabras de Diógenes puede hacernos perder de vista las consideraciones más elementales sobre el conocimiento intelectual formuladas por él. Por este motivo, merece la pena atender a la interpretación de Laks, dado que él otorga prioridad a la dimensión cognoscitiva de la teoría de nuestro presocrático frente a su faceta teleológica. Existe gran analogía entre las presentaciones realizadas por este investigador sobre el nous de Anaxágoras y sobre la noesis de Diógenes. En sus estudios sobre el primero, afirma que existiría una suerte de paralelismo entre la actividad del Intelecto y el devenir cósmico: el nous llevaría a cabo la discriminación de los ingredientes mezclados, porque precisamente en ello estriba — según Laks — toda actividad intelectual, a saber, en el discernimiento; además, el nous obraría sobre el mundo produciendo una circulación análoga al proceder in-

11. Cf. Torrijos-Castrillejo, ibidem, 289.

12. Cf. ibidem, 255-257. 
telectual en general, el cual — por reflexivo— sería de suyo 'circular' tal como después Platón expresaría con más claridad aun ${ }^{13}$.

Al tratar la noesis de Diógenes, Laks piensa que la circularidad se encuentra en otro plano. Naturalmente, la inteligencia según Diógenes no puede tener una función discriminativa, pues su sistema impide la división estricta entre unas cosas y otras. Ahora bien, aun así existiría circularidad en la historia completa del cosmos, puesto que la labor intelectual transformaría las cosas hasta refundirlas de nuevo en el estado inicial, retrotrayéndolas a su prístino estado de aire cálido. Esto significaría que

la inteligencia de Diógenes, al pertenecer al aire, retorna sobre sí misma en el mismo movimiento que realiza el aire en una especie de proceso reflexivo que podría ser considerado una anticipación [...] de una especulación posterior sobre la naturaleza de la intelección donde ésta aparece esencialmente unida a la circularidad ${ }^{14}$.

13. "Nov̂ $\varsigma$ governs animal life as well as world-formation because it is a critical faculty. For to know or to understand is basically to distinguish-in Greek x@íveıv, and the Anaxagorean cosmogonical process itself is nothing but a critical process, a

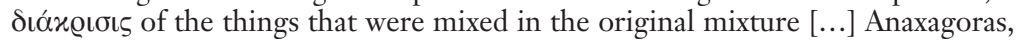
while being the first of a long series of thinkers to associate vov $\varsigma$ with circular movement, does so from a perspective which runs contrary to the very tradition he initiated. His rotation is not so much the symbol of identity we find in Plato and the whole Platonic-Aristotelian tradition, as a power of identification whose violence resembles that of the whirl with which it has rightly I think, been identified". A. LaKs, Mind's Crisis. On Anaxagoras' Nous, "Southern Journal of Philosophy" 31 Supplement (1993) 29-30; cf. TORRIJOS-CaSTRILlEJO, Anaxágoras y su recepción en Aristóteles cit., 211, nota 42). El autor que más claramente ha identificado el nous de Anaxágoras con la perichóresis quizá haya sido B. WiśnIEWski, Sur Anaxagore, "Quaderni Urbinati di Cultura Classica" 5 (1968) 153-159.

14. "In any case, Diogenes' return of the principle to itself, which does fall under the Aristotelian scheme, is also the only one, in the history of early Greek philosophy, which is linked to a noetic activity. This is, in my opinion, a most important point. For it means that Diogenes' intelligence, because it belongs to air, comes back to itself in the same movement as air does, in a sort of reflective process that might be considered as anticipating-in a resolutely cosmological (and thus once more metaphorical) fashion - some later speculation about the nature of intellection, where it appears to be essentially linked with circularity: according to Plato, circular movement is the image of intellection, and for Aristotle, the intellect thinks itself" (A. LAKs, Speculating about Diogenes cit., 358). 
Por consiguiente, la noesis de Diógenes puede ser vista como una respuesta a Anaxágoras, en cuanto la inteligencia no tendría como oficio propio el discernimiento, sino más bien "pensar su propia identidad"15.

La interpretación de Laks puede contener alguna verdad, sobre todo si tenemos en cuenta la similitud entre el verbo usado por Dió-

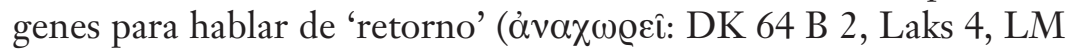
28 D 3) y el empleado por Anaxágoras para referirse al movimiento

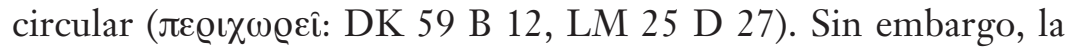
tesis de Laks no explica de modo satisfactorio el fragmento donde se afirma expresamente que la circularidad provocada por la inteligencia constituye más bien cierto 'equilibrio dinámico' que supondría el retorno sucesivo de las estaciones:

Porque, sin inteligencia, esto no estaría distribuido de tal modo que poseyera las medidas de todo: del invierno y del verano, de la noche y del día, de las lluvias, de las nubes y de las escampadas. Igual sucede con las demás cosas, si uno quiere detenerse a considerarlo, descubrirá que está ordenado del mejor modo posible $^{16}$.

¿La misma inteligencia que pretendería — según Laks - arrastrar los entes a la homogeneidad primigenia es la que produce, durante

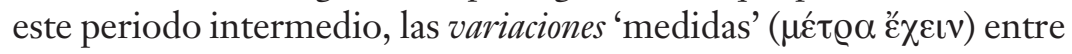
unas épocas y otras? Está claro que la racionalidad presente en el

15. "If the interpretation of Anaxagoras that I have sketched here is correct, Diogenes' scheme is plausibly interpreted as a pointed reply to it: what intelligence aims at is not the separation of independently existing things (discriminating them) but the coming back to what it itself is, which amounts, in some sense, to thinking its own identity" (LAKS, Speculating about Diogenes cit., 358). De modo análogo, se ha dicho: "Air is intelligence itself; pure thought intuitively thinking itself". J. Dockstader, Diogenes of Apollonia en J. Fieser, B. Dowden (eds.), Internet Encyclopedia of Philosophy (2011), http://www.iep.utm.edu/diogen-a/ [29/2/2016]).

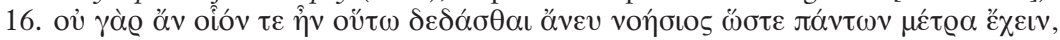

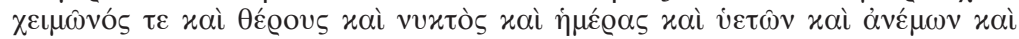

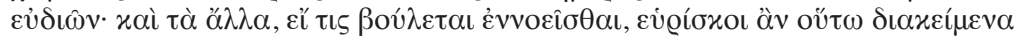

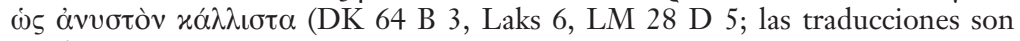
mías). 
curso de las estaciones no reside — a los ojos de Diógenes - en el retorno al punto inicial sino principalmente en los límites establecidos para dichos episodios. En otras palabras, aquí la inteligencia parece provocar más división que unión.

Esta exposición de Laks, para quien la inteligencia es pensamiento presente a sí mismo, podría ser confirmada por un hecho del cual no cabe duda, a saber, que, a diferencia del nous de Anaxágoras, la noesis de Diógenes pertenece al aire. No es una realidad independiente de la mezcla, tal como el de Clazomene describió su principio moviente, sino más bien una característica ínsita en el principio material ${ }^{17}$. Sin embargo, cuando Diógenes teje su raciocinio y se apoya en la inteligencia para explicar las características de los seres naturales (DK 64 B 5, Laks 9, LM 28 D 10), no apela a ella para consolidar la identidad del aire consigo mismo, la cual está exigida por sus planteamientos dinámicos (DK 64 B 2, Laks 4, LM 28 D 3), sino que la inteligencia explica principalmente la variedad de entidades en el mundo. Enseguida volveremos sobre esto.

Por otro lado, no debemos olvidar los estudios que han relativizado el protagonismo del aire en la argumentación de Diógenes. Ciertamente, resulta difícil sostener una tesis extrema como la de Barnes $^{18}$, el cual niega al aire el carácter de principio último de la realidad y llega a hablar incluso de una suerte de materia prima ante litteram. Son más atendibles las reconstrucciones del razonamiento de Diógenes ofrecidas por Graham ${ }^{19}$ y McKirahan ${ }^{20}$. Según ellos, este raciocinio no partiría del aire como principio último de la realidad sino más bien del monismo material para sentenciar primero que éste exige inteligencia (noesis) en el primer principio: sólo en segundo lugar se concluiría que la inteligencia debe ser identificada con el aire en virtud de las potencialidades que la naturaleza de éste encierra.

En definitiva, podemos sospechar que, a la hora de introducir el aire en su sistema, Diógenes no piensa primordialmente en la

17. Cf. A. LaKs, Speculating about Diogenes cit., 358.

18. Cf. op. cit., 576.

19. Cf. D. W. Graham, Explaining the Cosmos cit., 286.

20. Cf. R. D. McKirahan, Philosophy Before Socrates: An Introduction With Texts and Commentary (Hackett Publishing, Indianapolis, 2010) 346-347. 
identidad de esta sustancia consigo misma, tal como aseveraba Laks, sino, como veremos, presta atención ante todo a las diferencias presentes en esos mismos seres. Es ésta la cuestión más importante que habremos de tratar en lo que sigue.

\section{DiÓGENES, FILÓSOFO DE LA DIFERENCIA}

No deja de encerrar alguna ironía calificar a un monista material de 'filósofo de la diferencia', pero lo hacemos con el objeto de poner ante nuestros ojos cierta paradoja encerrada en el planteamiento de Diógenes que se hace patente al examinar su concepción de la inteligencia, la cual, como estamos viendo, explica más la variedad que la uniformidad ${ }^{21}$.

Comencemos remitiéndonos a Stokes ${ }^{22}$ y a Graham ${ }^{23}$ para sostener que Diógenes no podía concebir su pensamiento al margen de las incisivas argumentaciones de Parménides, quien marcó la historia de la filosofía presocrática y aun el pensamiento posterior definitivamente. El inquietante pensador eleático había expresado que

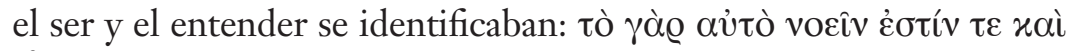
عiv $\alpha \iota^{24}$. Se trata, en palabras de Aristóteles, de una suerte de 'monismo

21. Creo que un 'filósofo de la diferencia' como Deleuze viene a expresar una interesante crítica de una comprensión de la circularidad similar a la de Laks, ajustándose algo más al aspecto del peculiar espíritu de Diógenes que queremos poner de manifiesto aquí: "L'éternel retour, selon Nietzsche, n'est pas du tout une pensée de l'identique, mais une pensée synthétique, pensée de l'absolument différent hors de la science un principe nouveau. Ce principe est celui de la reproduction du divers en tant que tel, celui de la répétition de la différence : le contraire de «l'adiaphorie ». Et, en effet, nous ne comprenons pas l'éternel retour tant que nous en faisons une conséquence ou une application de l'identité. Nous ne comprenons pas l'éternel retour tant que nous ne l'opposons pas d'une certaine manière à l'identité. L'éternel retour n'est pas la permanence du même, l'état de l'équilibre ni la demeure de l'identique. Dans l'éternel retour, ce n'est pas le même ou l'un qui reviennent, mais le retour est lui-même l'un qui se dit seulement du divers et de ce qui diffère”. G. Deleuze, Nietzsche et la Philosophie (Presses Universitaires de France, Paris, 1962) 52-53.

22. Cf. S. T. STOKES, op. cit., 238-244.

23. Cf. D.W. Graham, Explaining the Cosmos cit., 279-284.

24. DK 28 B 3, LM 19 D 6, 8; cf. DK 28 B 6, 6 (LM 19 D 7, 6); B 8, 8, 17 (LM 19 D $8,13,22)$; B 8, 35-36, 50 (LM 19 D 8, 40-41, 55). 
lógico ${ }^{25}$ que quizá debería ser interpretado, según la propuesta de Curd, como un 'monismo predicativo"26. Sin embargo, no es nuestro propósito aquí elucidar cuál fuera la intención de Parménides al pronunciar tales palabras sino más bien cómo pudieron ser acogidas por el pensamiento posterior. Es claro que la generación de filósofos que lo sucedió estaba persuadida de estar legitimada para hacer una aplicación 'cosmológica' de las tesis 'metafísicas' de Parménides. En este sentido, ¿cómo pudo entender Diógenes aquella sentencia de Parménides si es que se la apropió de algún modo? Cuando estudié a Anaxágoras — ese filósofo que hace de intermediario entre ellos dos-, me pareció advertir en él una concepción del noein heredera de Parménides por cuanto hablaba de penetrar la realidad allende sus apariencias ${ }^{27}$, además de compartir algunos rasgos en su manera de concebir los factores fisiológicos implicados en la intelección ${ }^{28}$. Sin embargo, creo que el principal punto común que nos permitirá esclarecer la recepción en Diógenes de este aspecto del pensamiento de Parménides será después explicitado por Platón y por Eudoxo ${ }^{29}$. Se trata del 'idealismo' que puede sugerir la afirmación de Parménides: la realidad se compondría de 'aspectos ${ }^{30}$, los cuales pueden ser entendidos ya como contenidos de actos cognoscitivos ya como rasgos reales de las cosas. Naturalmente, este 'idealismo’ no tiene por qué ser visto de manera espiritual sino que, de hecho, Diógenes lo interpreta de un modo material, es decir, sin convertir los cuerpos en 'ideas' sino más bien haciendo del entendimiento un ente corpóreo.

En este sentido, si hay alguien que se tome en serio las palabras de Parménides, ése es Diógenes cuando lleva a efecto en los cuerpos

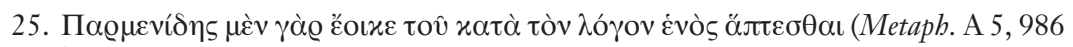
b 18).

26. Cf. P. Curd, The Legacy of Parmenides (Princeton University Press, Princeton, 1998) 66.

27. Cf. D. Torrijos-Castrillejo, Anaxágoras y su recepción en Aristóteles cit., 195, 216.

28. Cf. ibidem, 34.

29. Cf. ibidem, 318, 320-321.

30. Nótese que tanto Anaxágoras (DK 59 B 4a, LM 25 D 13) como Diógenes (DK 64 B 5, Laks 9, LM 28 D 10) utilizan el término idé $\alpha$ con el sentido de 'aspecto';

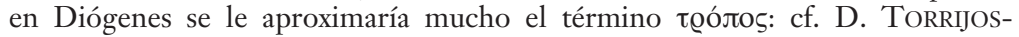
Castrillejo, ibidem, 391-392, nota 8. 
lo que después hará Platón en el mundo de las Ideas. En efecto, desarrolla una hermenéutica de Parménides inversa a la seguida por Meliso, la cual se ha impuesto empero como 'punto de vista eleático' por excelencia. Según Meliso, puesto que el ser es idéntico al pensamiento y éste nos demuestra indubitablemente la unicidad del ser, entonces la variedad ha de ser una mera apariencia. Diógenes piensa,

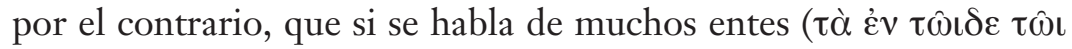

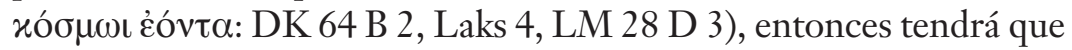
haber tantos actos de entenderlos cuantos ellos sean (vó $\sigma \iota \varsigma$ ло $\lambda \lambda \eta \dot{\eta}$ : Laks 3, LM 28 D 5b). La filosofía de Diógenes podría constituir una interpretación no monista del pensamiento de Parménides, algo que hoy en día va resultando cada vez menos implausible. Veamos, pues, las palabras mismas de Diógenes que dan pie a esta interpretación:

Según me parece, aquello que está en posesión de la inteligencia es lo mismo que es llamado aire entre los hombres; por él son gobernadas todas las cosas y domina sobre todas. Creo que éste es dios y se desliza por todas partes, dispone todo y está en todo. No existe una sola cosa que no participe de él; pero ni una sola participa de modo semejante a otra, sino que son múltiples los modos de éste, es decir, del aire y de la inteligencia. En efecto, le corresponden muchos modos: más caliente y más frío, más seco y más húmedo, más estable y [también le corresponde] poseer veloz movimiento, y hay asimismo en él otros muchos rasgos distintivos de infinitos sabores y colores. El alma de todos los vivientes es también lo mismo, a saber, aire más cálido que aquel en el cual nos encontramos, pero mucho más frío que el que se halla cabe el sol. El calor no es semejante en ninguno de los vivientes, pues ni siquiera es el mismo entre unos hombres y otros; sin embargo, como no difiere demasiado, son bastante similares. Aun así, ninguna cosa distinguible puede generarse y ser exactamente semejante a otra distinta, a menos que sea generado lo mismo. Por tanto, siendo la distinción de muchos modos, también habrá muchos vivientes de muchos modos y, entre ellos, no será semejante ningún aspecto, género de vida o inteligencia, debido a la can- 
tidad de sus rasgos distintivos. No obstante, todos viven, ven y oyen gracias a lo mismo y todos reciben de lo mismo cualquier otra inteligencia ${ }^{31}$.

Estas líneas nos permiten ver cómo el 'idealismo material' de Diógenes prepara el de Platón, en virtud de su reinterpretación de Anaxágoras. El Clazomenio había expresado que las cosas 'participan'

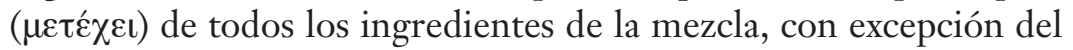
Intelecto (DK 59 B 11-12, LM 25 D 26-27). Sin embargo, Diógenes hace de la noesis el principio que proporciona su carácter peculiar a cada una de las diferencias que surgen en el aire; pero lo hace de manera inmanente, poniéndose la noesis misma como diferencia. En este sentido, no sólo no puede ser ajena a las cosas generadas por ella sino que, por el contrario, todo tiene que 'participar' de la noesis. Al unir la inteligencia con los contenidos eidéticos presentes en la realidad, está convirtiendo ésta en una especie de 'mundo de las Ideas material' en que todas 'participan' de un solo principio, no la Idea del Uno-Bien, sino el uno-aire.

El fragmento citado pone de relieve también que el interés primordial de Diógenes al hablar de la noesis es mostrar la pluralidad de la realidad $\mathrm{y}$ - pese al parecer de Laks - no lo es tanto aquel retorno a la unidad del cual se habla en DK 64 B 2, Laks 4, LM 28 D 3. Por

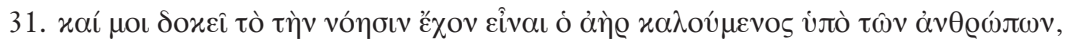

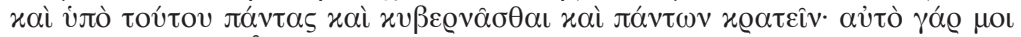

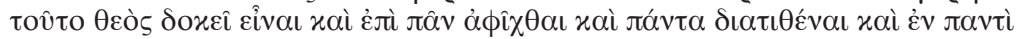

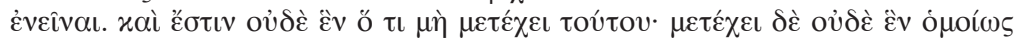

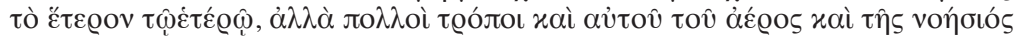

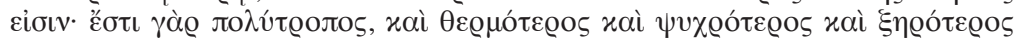

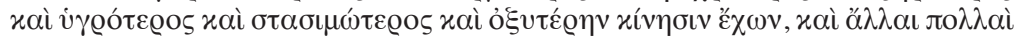

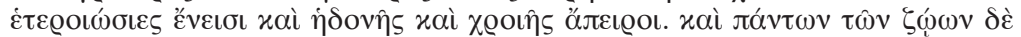

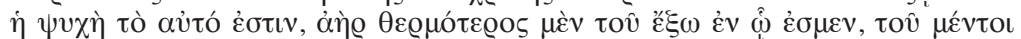

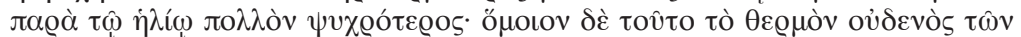

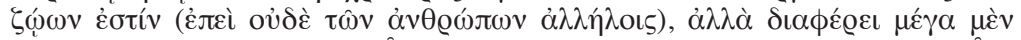

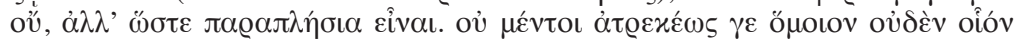

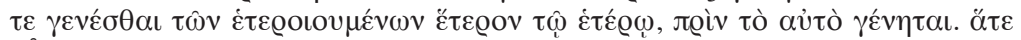

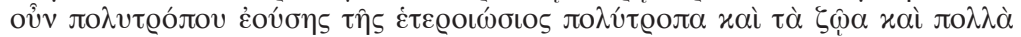

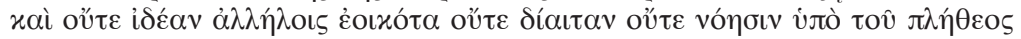

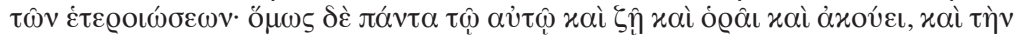

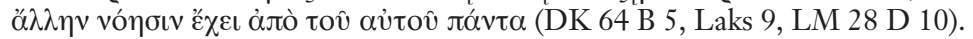


esta razón, nos sentimos justificados para designar a Diógenes como 'filósofo de la diferencia'. En efecto, la 'diferencia' es precisamente uno de los conceptos a los que presta más atención, hasta el extremo de acuñar un nuevo término para expresarla. Sorprendentemente, éste es un hecho poco atendido por la crítica $^{32}$, pero en el fragmento

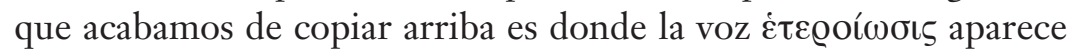
por vez primera en la literatura griega transmitida hasta nosotros (¡y lo hace tres veces!): viene a significar 'alteración' en el sentido de 'diferencia' o 'distinción', pero es empleado por Diógenes con el preciso matiz de 'rasgo distintivo', tal como he traducido en dos de esas apariciones en dicho fragmento. Es 'alter-ación' en cuanto una

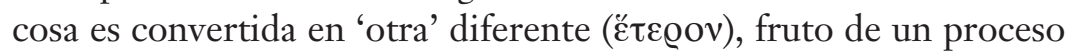
de 'transformación'. En contraste con Meliso, que también utiliza los mismos verbos, los cambios en la realidad no son para Diógenes meramente aparentes, sino auténticas mutaciones del aire, el cual es sujeto del 'transformarse' ( $\mu \varepsilon \tau \alpha \pi i \pi \tau \varepsilon ı v$; también aparece

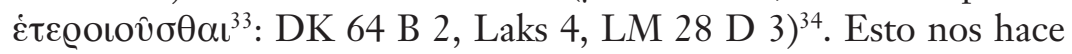
prestar atención al peculiar modo de delimitar el monismo por parte de Diógenes.

Nuestro autor insiste sobre todo en la unicidad del principio (y del término) de todo. Afirma que las cosas son 'diferenciadas'

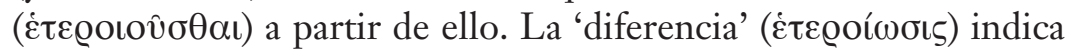

32. Diller sí se hizo eco de esta circunstancia: cf. H. DiLler, Die philosophiegeschichtliche Stellung des Diogenes von Apollonia, "Hermes" 76 (1941) 361. Es admirable que ni Cappelletti ni Laks se hayan referido a ello en sus respectivos comentarios a este fragmento (Á. J. CappelletTi, Los fragmentos de Diógenes de Apolonia cit., 76-80; A. LAKs, Diogène d'Apollonie cit., 82-91).

33. "He uses the unusual word heteroiousthai, 'be altered' or 'be differentiated', evidently a term of art. This same term appears in Melissus. The most obvious person to have invented the term is Diogenes, who wishes to talk about a restricted kind of change, something like Aristotle's alteration or change of quality". D. W. Graham, The Texts of Early Greek Philosophy (Cambridge University Press, Cambridge, 2010) 458, 4 [F2]. Sin embargo, también este autor ignora la

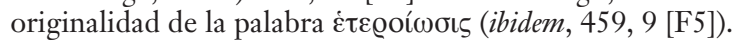

34. "Für Diogenes sind die Dinge, zu denen die empedokleischen Elemente gehören, solche, die in unserem Kosmos als seiend erscheinen [...], kein Irrtum der Menschen, sondern anerkannte Phänomene" (H. Diller, op. cit., 362). "Für ihn ist das Seiende Luft, die die verschiedensten Wandlungen erfährt, ein Identisches,

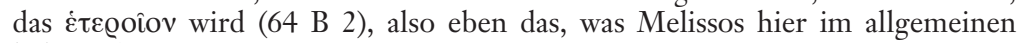
bekämpft" (ibidem, 366). 
la variedad en los entes del mundo. Sin embargo, el origen y el final de las cosas es uno solo. Esto es designado cuando se afirma que aquel proceso de diferenciación procede 'de lo mismo' (ảjò tô̂ aữô̂: DK 64 B 2, Laks 4, LM 28 D 3), pero también cuando dice

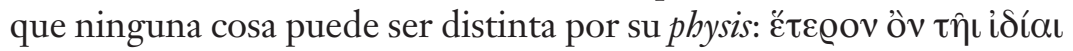
фú $\sigma \varepsilon$ (ibid.), unas palabras que se suelen traducir como: "diferente por su propia naturaleza" 35 . Sin embargo, semejante traducción de un término cuyo uso no parece ser técnico, tratándose de un autor de este periodo, sólo puede dar lugar a confusión. Con esas palabras Diógenes está indicando que las cosas no pueden tener diferentes orígenes sino uno solo; en ese momento no se ocupa de su simultaneidad a la transformación, una permanencia del aire bajo los cambios. Esta persistencia es expresada al decir que todas las cosas "son

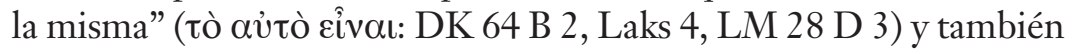
al relativizar el significado del mismo verbo usado para hablar de la

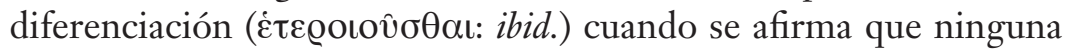

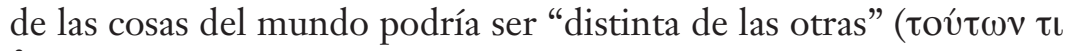

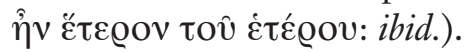

Está claro, las cosas proceden de un solo principio y en él derivan al descomponerse; es más, en último término no son 'distintas' de él. Sin embargo, en el fragmento que antes habíamos citado en su íntegra extensión, sobre todo se insistía en la disconformidad entre unas cosas y otras. No sólo no se hablaba de su semejanza sino que se acentuaba su diferencia hasta el punto de igualar - por decirlo en palabras aristotélicas - desigualdad numérica con desigualdad específica: " $[\mathrm{N}]$ inguna cosa distinguible puede generarse y ser exactamente semejante a otra distinta, a menos que sea generado

35. Cf. A. Bernabé, Fragmentos presocráticos de Tales a Demócrito (Alianza, Madrid, 2008) 267. De un modo semejante proceden, por ejemplo, Obinu, Laks y Graham: “[...] altra per propria natura". S. OBINU, en G. Reale (ed.), I presocratici (Bompiani, Milano, 2006) 1133; "[...] étant différente par sa nature propre" (A. LAKs, Diogène d'Apollonie cit., 62); “[...] being other in its own nature" (D. W. GRAHAM, The Texts cit., 439). Menos adecuadas todavía me parecen las traducciones de Cappelletti y Rechenauer: "[...] diferente por su propia substancia" (Á. J. CAPPELLETTI, Los fragmentos de Diógenes de Apolonia cit., 65); “[...] verschieden aufgrund seines eigenen Wesens". G. Rechenauer, Diogenes aus Apollonia en H. Flashar, D. Bremer, G. Rechenauer (eds.), Frühgriechische Philosophie (Schwabe, Basel, 2013) 816 . 
lo mismo". Esta sentencia explicaba lo que se acababa de decir, a saber, que no existen lo que Aristóteles llamaría 'especies': "El calor no es semejante en ninguno de los vivientes, pues ni siquiera es el mismo entre unos hombres y otros; sin embargo, como no difiere demasiado, son bastante similares". He aquí una postura cercana al heraclitismo de Cratilo (DK 65, 3-4), aunque el problema de la inefabilidad de cada cosa no se sitúe para Diógenes sobre todo en la fluidez de lo real, sino en la singularidad de cada ente, la cual es ajena a toda comunidad como no sea la del aire (uno piensa enseguida en las posturas nominalistas muy posteriores). Diógenes es un defensor tan acérrimo de la 'diferencia' que considera que ninguna alteridad puede ser meramente de número, un sumar en cantidad otros seres de la misma índole del primero, sino que debe consistir siempre en una variedad. Todo ente es diferente de todos los demás, no sólo numéricamente distinto de sus semejantes.

Esta defensa de la 'diferencia' podría ser una réplica a Anaxágoras. Ambos tratan de defender los planteamientos de Parménides pero lo hacen de modo muy dispar. Anaxágoras intenta salvar la inmutabilidad del ente haciendo de los ingredientes de su mezcla realidades incapaces de cambiar y, así, todo lo que llegará un día a ser debía estar ya presente en la mezcla desde antes del inicio de la historia. El movimiento produce cierta heterogeneidad en la mezcla de manera que unas cosas sobresalgan cuantitativamente y asílleguen a hacerse manifiestas. No obstante, al agruparse ciertos ingredientes en determinadas zonas, los demás nunca son enteramente retirados de ninguno de los entes generados. Esto implica una curiosa homogeneidad en los entes, los cuales son siempre similares entre sí, porque todos están mezclados con todos de idéntico modo ${ }^{36}$. También la mezcla de Anaxágoras es en este sentido 'monista', pues todas las cosas son 'similares', también para él 'todo es lo mismo'; pero, atención, las cosas son similares ¡en tanto en cuanto son 'diversas' de sí mismas!, es decir, incluyen en sí toda la variedad efectivamente

36. Cf. D. Torrijos-Castrillejo, Anaxagorae bomoeomeria, "Elenchos" 36 (2015) 141-147. 
presente en la realidad. Por eso, esta "homología"37 en la mezcla que sufren todos los entes no impide que también Anaxágoras piense que

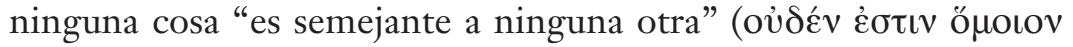
oủdeví: DK 59 B 12, LM 25 D 27). Diógenes, por su parte, es más extremado que Anaxágoras, porque insiste en que no se puede encontrar en dos sitios diferentes una semejanza estricta, ni siquiera entre dos aspectos de una misma cosa; esto es, Diógenes podría estar atacando la idea de 'ingrediente' como tal, al parecer aceptada por Anaxágoras cuando habla de 'partes' ( $\mu$ oî@ $\iota)^{38}$.

Las 'partes' de Anaxágoras son sustituidas por los 'rasgos dis-

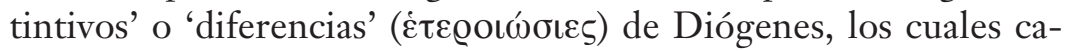
recen de entidad por ellos mismos y por eso también carecen de identidad; son, precisamente, otredades. Para subrayar su carácter de-

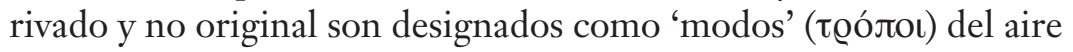
y de la inteligencia. Es, pues, precisamente la inteligencia a la que se debe esta pluriformidad de la que es capaz el aire. En este sentido, si comparamos las siguientes palabras de Laks con las páginas suyas que antes comentamos, lo vemos mostrarse más exacto aquí. Ahora afirmará que, a diferencia del nous de Anaxágoras, el cual no produce la identidad de los ingredientes de su mezcla, la "noesis de Diógenes actúa propiamente como 'intelección' [...] porque no separa lo que ya está ahí sino que limita u 'organiza' la diferenciación de un principio único llamado aire. Y si puede limitarla, es porque está 'dentro'. A las 'partes' [...] de Anaxágoras se ha sustituido la inmanencia del pensamiento" ${ }^{39}$. Efectivamente, Diógenes niega toda identidad

37. Cf. C. Louguet, Anaxagore : Analogie, proportion, identité, "Philosophie antique" $13(2013) 119$.

38. Cf. D. Torrijos-Castrillejo, Anaxágoras y su recepción en Aristóteles cit., 287.

39. "L'intelligence [d'Anaxagore] n'agit donc jamais comme intelligence [...]. La noésis chez Diogène agit proprement comme 'intellection' (et non comme origine du mouvement), parce qu'elle ne sépare pas ce qui est déjà là, mais qu'elle limite, ou 'organise' la différentiation d'un principe unique, appelé air. Et si elle peut la limiter, c'est qu'elle est 'dedans'. Aux 'parts' infinitésimales d'Anaxagore s'est substituée l'immanence de la pensée" (A. LaKs, Diogène d'Apollonie cit., 36). Ya manifesté mi desacuerdo con Laks respecto de Anaxágoras en D. ToRRIJOsCastrillejo, Anaxágoras y su recepción en Aristóteles cit., 207-214. A ello añado ahora que tampoco veo por qué habría que negar al aire-inteligencia de Diógenes la índole de moviente, dado que afirma que el 'ritmo cósmico' es originado 
originaria fuera de la del aire-inteligencia, con lo cual otorga a este principio una creatividad mucho mayor de la que poseía el nous de Anaxágoras, puesto que ahora toda diferencia se debe a la versatilidad de la inteligencia. Ya no ha de reconocer nada anterior a ella, tan sólo ha de devenir distinta de sí misma, originando nuevas maneras

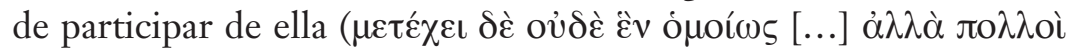

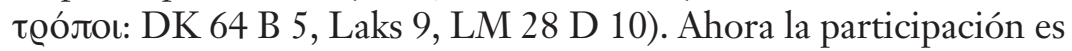
modificable, no está fijada como en el sistema de Anaxágoras, donde las cosas siempre debían participar de la misma manera de todas las

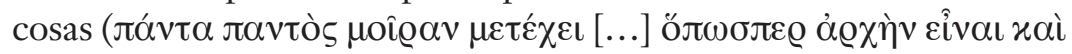

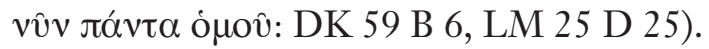

Diógenes también critica otro aspecto del nous de Anaxágoras. Antes decíamos que, para el Clazomenio, ninguna cosa era semejante a ninguna otra... 'excepto el nous' (DK 59 B 12, LM 25 D 27) que es siempre igual, siempre semejante a sí mismo, con independencia de su grado de intervención en la realidad, de su mayor o menor efectividad ${ }^{40}$. Todo lo contrario opina Diógenes respecto de la noesis, la cual es justamente el principio de diversificación de las cosas en virtud de su propia variabilidad. El nous de Anaxágoras debe permanecer con su identidad constante que le asegura una total exención de la mezcla, así es del todo distinto de cuanto en ella hay, y puede conocer y dominar todas las cosas. El conocimiento y el poder de la noesis de Diógenes estriba también en su identidad consigo misma y con todo cuanto puede producir, precisamente porque este filósofo defiende tesis dinámicas del todo diversas de Anaxágoras: mientras que, según éste, la desemejanza era condición para intervenir sobre lo ajeno ${ }^{41}$, Diógenes sostiene el punto de vista

por él (DK 64 B 3, Laks 6, LM 28 D 5b), que el movimiento es propio del aire

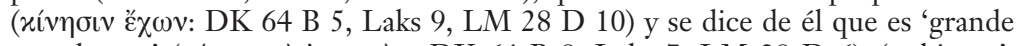

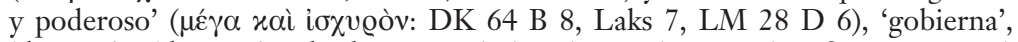

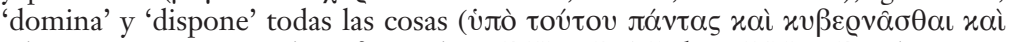

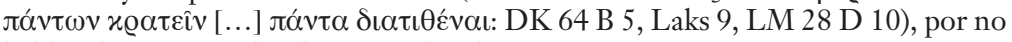
hablar de su especial influencia sobre los vivientes, cuyos 'comportamientos' son

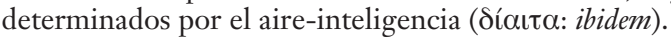

40. Cf. D. Torrijos-Castrillejo, Anaxágoras y su recepción en Aristóteles cit., 187188.

41. Cf. ibidem, 97-98, 202. 
opuesto, es decir, que tan sólo lo semejante puede obrar sobre lo semejante (DK 64 B 2, Laks 4, LM 28 D 3). De este modo, la identidad consigo mismo del nous de Anaxágoras y la identidad consigo misma del aire-inteligencia de Diógenes tienen un desarrollo bien divergente en sus respectivas doctrinas ${ }^{42}$.

\section{Conclusiones}

¿Cómo no ver en el aire inteligente de Diógenes el principio que es, a la vez, 'uno y muchos' sobre el cual nos hablará Aristóteles a la luz de las reflexiones de Platón? Se trata de un ser dotado de inteligencia para asir en sí la muchedumbre de las cosas porque es todas las cosas. El carácter de inteligente no tiene principalmente el cometido de homogeneizar las cosas, como decía Laks, sino más bien

42. Lamento haber omitido aquí el estudio detallado del valioso testimonio de Teofrasto (DK 64 A 19, LM 28 D 35-36, 38-39, 42-44), donde habla del conocimiento en general y de la fisiología del pensamiento. Sobre ese texto, dice

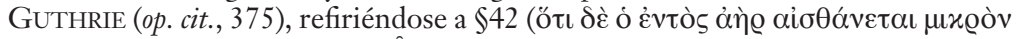

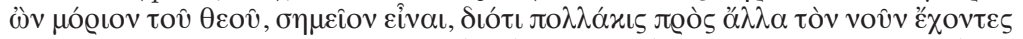

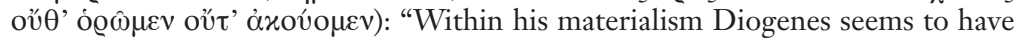
come nearer than any other fifth-century philosopher to the distinction between a physical and a psychological event which was clearly drawn by Aristotle". Sus palabras contrastan con mi afirmación: "Diógenes interpreta de una manera física el 'estar presente cognoscitivamente' las cosas en el intelecto" (D. TorRIJOsCASTRILlejo, Anaxágoras y su recepción en Aristóteles cit., 286), presencia que empero creí ver verificada de un modo 'no material' en el nous de Anaxágoras (ibidem, 213214). Creo que también Diógenes aprecia la dimensión activa de la inteligencia, es decir, la entiende como un tipo de operación en la que el cognoscente interviene activa y no sólo pasivamente. Sin embargo, al hacer de toda percepción una modificación física en el principio material (y viceversa: ¡las modificaciones físicas pueden ser comprendidas como 'percepciones'), pierde de vista la separación que tiene que haber entre cognoscente y conocido: el poseer cognoscitivo debe ser de una índole no física y es justo eso lo que niega Diógenes al hacer de la inteligencia una propiedad del aire. En todo caso, las palabras de Diógenes en esa parte del testimonio muestran la misma paradoja suscitada al negar sensación a las plantas (\$44) y, en general, al reducir el conocimiento bajo determinadas circunstancias: al parecer, Diógenes pensaba que en ciertas condiciones el aire no ejercitaba su operación propia, cosa que resulta contradictoria con su comprensión del aire como un dios omnisciente presente en todas las cosas (DK 64 B 8, Laks 7, LM 28 D 6). ¿Es que el aire presente en las plantas y en las cosas 'inanimadas' conoce aunque éstas no lo hagan? Pero aquí el problema de fondo es la total indiferencia ante la subjetividad en cuanto tal, puesto que se ignora por completo la conciencia, ya de la divinidad, ya la de los otros sujetos, ya la ausencia de conciencia. 
todo lo contrario. El principio único, precisamente en virtud de su inteligencia, puede diferenciarse en una amplia variedad de formas sin perder su identidad originaria. El entendimiento es principio de multiplicidad como después Plotino repetirá con vehemencia, si bien la inteligencia de Diógenes sobre todo recuerda a la de Spinoza, como ya advirtió Bayle; en efecto, de modo análogo aquel sefardí creía que las cosas no eran sino 'modos' (modi) de la única sustancia divina ${ }^{43}$.

Bien pensado, no es extraño que a Diógenes la inteligencia le haya llevado a la variedad, del mismo modo como a Anaxágoras el nous le había ayudado a dar unidad al mundo. La noesis de Diógenes disgrega el aire en una multiplicidad de facetas, mientras que el nous de Anaxágoras, precisamente al discriminar, en realidad logra reunir lo que se hallaba disgregado: al separar lo desemejante, pone lo semejante con lo semejante. Anaxágoras es un pluralista y necesita explicar la unidad, mientras que Diógenes, precisamente por ser monista, tiene que justificar la variedad. Así, la inteligencia de Diógenes establece variedad y diversidad allá donde, al fin y al cabo, sólo hay unidad. El resultado es justo el contrario del expresado por Laks: no la homogeneización sino la diversificación. Tenía razón Laks al afirmar que la función filosófica del noein en ambos sistemas es muy diferente pero esto no se verifica precisamente como dice él. Si hay algo que no caracteriza la noesis de Diógenes es la identidad. En cuanto la inteligencia entra en su sistema, se cuela con ella la multiplicidad, pese a la permanencia de la identidad salvaguardada por el principio material.

La insistencia de Laks en la 'identidad' de la noesis consigo misma da pie a un último apunte. Este estudioso dice remitirse a la circularidad del pensamiento según Platón pero a nadie se le escapan las similitudes de su interpretación con la concepción 'moderna' del sujeto. Se diría que Diógenes se aleja bastante de una comprensión de

43. Cf. G. PiaIA, Philosophical Historiography in France from Bayle to Deslandes, en G. Santinello, G. Piaia (eds.), Models of the History of Philosophy (Springer, Dordrecht/Heidelberg/London/New York, 2010) vol. 2, 121. Esta comparación ha vuelto a ser propuesta por CAPPELLETTI, Los fragmentos de Diógenes de Apolonia cit., 25. 
la subjetividad característica de la modernidad. También Anaxágoras prescindía de la realidad independiente de cada conciencia individual al hacer del sujeto particular una mera manifestación de un solo Intelecto; pero, al menos, este Intelecto mantenía cierta identidad consigo mismo. Por el contrario, Diógenes resulta mucho más 'postmoderno' que Anaxágoras — si se me permite el anacronismo- ya que, pese a recalcar la unidad material del sujeto de cada acto intelectual, desmiembra la actividad intelectual en un número indefinido de 'modos' que nunca son tampoco idénticos entre sí. Puede ser que se trate siempre de la misma realidad corpórea la que experimente esa variedad de 'estados de conciencia', sí, pero la 'conciencia' en cuanto tal no posee unidad alguna y justamente su índole no es la identidad sino la fragmentación. La inteligencia no parece, pues, estar presente a sí misma o, al menos, éste es un punto descuidado por Diógenes; tan sólo se podría pensar en la inteligencia pensándose a sí misma porque se supone que el filósofo hace uso de ella al escribir sus líneas dedicadas a estas cuestiones. Ciertamente, nuestro filósofo no se refiere únicamente a los contenidos inteligibles, sino que también habla del conocimiento ejercido por un sujeto (DK 64 B 3, 4, 5, 8, Laks 6, 8, 9, 7, LM 28 D 5, 9, 10, 6), pero siendo esta inteligencia una propiedad del principio único de todo, no le hubiera sido difícil expresar que, al pensar, el pensamiento se piensa a sí mismo; sin embargo, es significativo que no lo haya hecho. Por tal razón, hemos de concluir que la noesis de Diógenes está todavía bastante lejos de la 'inmanencia de la conciencia', pues para él lo primario es, sin duda, la inteligibilidad de lo real por delante de la autoconciencia del cognoscente.

\section{REFERENCIAS}

J. BARnes, The Presocratic Philosophers (Routledge, London, 1982).

A. BERnaBé, Fragmentos presocráticos de Tales a Demócrito (Alianza, Madrid, 2008).

Á. J. Cappelletti, Los fragmentos de Diógenes de Apolonia (Tiempo Nuevo, Caracas, 1975).

Á. J. Cappelletti, Diógenes de Apolonia y la segunda filosofía jónica (Universidad de Zulia, Maracaibo, 1976). 
P. Curd, The Legacy of Parmenides (Princeton University Press, Princeton, 1998).

G. Deleuze, Nietzsche et la Philosophie (Presses Universitaires de France, Paris, 1962).

H. Diller, Die philosophiegeschichtliche Stellung des Diogenes von Apollonia, "Hermes" 76 (1941) 359-381.

H. Diels, W. KranZ (eds.), Die Fragmente der Vorsokratiker (Weidmann, Berlin, 1951-1975).

J. Dockstader, Diogenes of Apollonia, en J. Fieser, B. Dowden (eds.), Internet Encyclopedia of Philosophy (2011), http://www.iep. utm.edu/diogen-a/ (29/2/2016).

K. VON FRITZ, NOY $\Sigma$, NOEIN, and Their Derivatives in Pre-Socratic Philosophy (Excluding Anaxagoras): Part I. From the Beginnings to Parmenides, "Classical Philology" 40 (1945) 223-242.

K. VON FRITZ, NOY $\Sigma$, NOEIN, and Their Derivatives in Pre-Socratic Philosophy (Excluding Anaxagoras): Part II. The Post-Parmenidean Period, "Classical Philology" 41 (1946) 12-34.

K. VON FRITZ, Der NOY $\Sigma$ des Anaxagoras, "Archiv für Begriffsgeschichte" 9 (1964) 87-102.

D. W. Graham, Explaining the Cosmos. The Ionian Tradition of Scientific Philosophy (Princeton University Press, Princeton, 2006).

D. W. Graham, The Texts of Early Greek Philosophy (Cambridge University Press, Cambridge, 2010).

W. K. C. GuThrie, A History of Greek Philosophy (Cambridge University Press, Cambridge, 1978) Vol. 2.

A. LAKs, Mind's Crisis. On Anaxagoras' Nous, "Southern Journal of Philosophy" 31 Supplement (1993) 19-38.

A. LAKs, Diogène d'Apollonie (Academia, Sankt Augustin, 2008).

A. LAKs, Speculating about Diogenes of Apollonia, en P. CURD, D. W. GRAHAM (eds.), The Oxford Handbook of Presocratic Philosophy (Oxford University Press, Oxford, 2008) 353-364.

A. Laks, G. W. Most (eds.), Les débuts de la philosophie. Des premiers penseurs grecs à Socrate (Fayard, Paris, 2016).

C. Louguet, Anaxagore: Analogie, proportion, identité, "Philosophie antique" 13 (2013) 117-145. 
R. D. McKirahan, Philosophy Before Socrates: An Introduction With Texts and Commentary (Hackett Publishing, Indianapolis, 2010).

G. PIAIA, Philosophical Historiography in France from Bayle to Deslandes, en G. Santinello, G. Piaia (eds.), Models of the History of Philosophy (Springer, Dordrecht/Heidelberg/London/New York, 2010) vol. 2, 93-176.

G. REALE (ed.), I presocratici (Bompiani, Milano, 2006).

G. Rechenauer, Diogenes aus Apollonia, en H. Flashar, D. Bremer, G. RECHENAUER (eds.), Frühgriechische Philosophie (Schwabe, Basel, 2013) 811-832.

S. T. STOKes, One and Many in Presocratic Philosophy (Oxford University Press, Washington, D.C., 1971).

W. TheILER, Zur Geschichte der teleologischen Naturbetrachtung bis auf Aristoteles (Karl Hoenn, Zürich, 1924).

D. Torrijos-Castrillejo, Anaxágoras y su recepción en Aristóteles (EDUSC, Roma, 2014).

D. Torrios-Castrillejo, Anaxagorae homoeomeria, "Elenchos" 36 (2015) 141-147.

B. Wiśniewski, Sur Anaxagore, "Quaderni Urbinati di Cultura Classica” 5 (1968) 153-159.

J. Zafiropulo, Diogène d'Apollonie (Les Belles Lettres, Paris, 1956). 